\title{
MIGRAÇÕES DO SÉCULO XXI: NOVAS PERSPECTIVAS
}

Leda Maria de Oliveira Rodrigues ${ }^{1}$

\section{Resumo}

O tema deste artigo tem sua origem em estudos realizados sobre a imigração atual para o Brasil. Partindo de algumas entrevistas com imigrantes atuais, oriundos da América do Sul, África, Ásia, Caribe, Oriente Médio e de outras localidades, observamos que a imigração atual não se trata mais de uma imigração laboral, simplesmente. Assim, considerando nossos dados e estudos priorizamos alguns autores que discutem outras possíveis formas de analisar e explicar a imigração hoje. Se a imigração não tem mais como razão fundamental o trabalho, o que então levaria os agentes a migrarem? Se outrora o trabalho foi uma das causas principais da imigração e hoje não mais, quais outros aspectos sociais poderiam ocasionar as imigrações contemporâneas, e como podemos, atualmente, analisar a imigração que por si só já é um elemento fundamental para a compreensão das sociedades que passaram e passam por esse processo. Partimos do trabalho de Castles (2010) que analisa a ideia de que a imigração não pode ser vista apenas como um problema sociológico; desenvolve a ideia de que esse é um fenômeno que envolve aspectos sociais, econômicos, políticos e, atualmente, problemas geopolíticos e fronteiriços. Não que esses dois últimos aspectos não fossem características de outros momentos migratórios, mas atualmente, com o avanço de um "novo imperialismo" (Harvey, 2008) impôs-se a ideologia de que não se trata de imperialismo e, sim, de um mundo globalizado no qual, teoricamente, as fronteiras não devem existir, ao menos no que diz respeito ao capital financeiro e às diversas formas de "acumulação" do capital. Mas as fronteiras continuam a existir para a "imigração não desejada" (Sayad; Bourdieu, 1998) e aí se impõem as preocupações geopolíticas. Segundo Castles (2010), na busca de uma teoria que pudesse vir a responder as razões das imigrações, aponta a insuficiência de uma só área de estudo para esse fenômeno. Afirma ser preciso considerar a pesquisa sobre imigração como um fenômeno social mais abrangente. Deve-se considerar a interdisciplinaridade para se ter uma visão da totalidade do fenômeno respondendo, por que o agente social migra dentro desse contexto atual? Certamente não são as mesmas razões que impulsionaram as migrações dos séculos passados e, se as razões mudaram, temos que responder por quê? E quais são as novas motivações. Isso

\footnotetext{
${ }^{1}$ Departamento de Fundamentos da Educação, PEPG em: Educação, História, Política, Sociedade - PUC-SP
} 
implica ter em consideração as ideias de neoliberalismo do século XXI e de globalização (Harvey, 2008) nas quais o mundo se insere na atualidade. Seriam as próprias transformações sociais que estimulam e mantêm os movimentos migratórios atualmente? O artigo busca apontar algumas das transformações sociais e suas supostas relações com a imigração para o Brasil.

Palavras-chave: Imigração do século XXI. Transformações sociais. Globalização. Imperialismo. Preocupações geopolíticas.

\section{Abstract \\ XXI $^{\text {th }}$ CENTURY MIGRATIONS: NEW PERSPECTIVES}

The theme of this article has its origin in studies carried out on current Brazilian immigration. Based on interviews with current immigrants from South America, Africa, Asia, the Caribbean, the Middle East, and other locations, we find that current immigration is no longer simply a matter of labor immigration. Thus, considering our data and studies, we prioritize some authors who discuss other possible ways of analyzing and explaining immigration today. If immigration does not have the fundamental reason for work, what would then lead the agents to migrate? If work was once one of the main causes of immigration and today no longer, what other social aspects could bring about contemporary immigration, and how we can now analyse immigration, which in itself is already a fundamental element for understanding the societies that have passed and go through this process. We start from the work of Castles (2010) that analyses the idea that immigration can not be seen only as a sociological problem; develops the idea that this is a phenomenon that involves social, economic, political aspects, and currently, geopolitical and frontier problems. Not that these last two aspects were not characteristic of other migratory moments, but today, with the advance of a "new imperialism" (Harvey, 2008), the ideology was imposed that it is not a question of imperialism but of a globalized world in which, theoretically, borders should not exist, at least as far as financial capital and the various forms of 'accumulation' of capital are concerned. But borders continue to exist for "unwanted immigration" (Sayad; Bourdieu, 1998) and there are geopolitical concerns. According to Castles (2010), in the search for a theory that could answer the reasons for immigration, it points out the insufficiency of a single area of study for this phenomenon. It states that immigration research needs to be considered as a more comprehensive social phenomenon. One must consider interdisciplinarity to have a view of the totality of the phenomenon, responding why does the social agent migrate within this current context? Certainly not the same reasons that 
pushed the migrations of past centuries and, if the reasons have changed, we have to answer why? And what are the new motivations. This implies taking into account the ideas of neoliberalism of the 16th century and globalization, in the $21^{\text {th }}$ century (Harvey, 2008) in which the world is inserted today. Are the social transformations themselves that stimulate and sustain migratory movements today? The article seeks to point out some of the social transformations and their supposed relations with Brazilian immigration.

Key Words: 21th century immigration. Social transformations. Globalization. Imperialism. Geopolitical concerns.

\section{Introdução}

O tema deste artigo tem sua origem principal em estudos realizados pelo grupo de pesquisa Movimentos Migratórios e Educação da PUC-SP² que tem como objetivo o estudo da relação entre a imigração brasileira atual e a educação. Os estudos procuram conhecer, com base em dados empíricos, as razões pelas quais os agentes sociais tomam a decisão de migrar para outros países, mas, principalmente, preocupa-se em conhecer a situação educacional das crianças estrangeiras matriculadas em nossas escolas públicas e privadas. No caso da imigração atual para o Brasil que vem se intensificando, - de 2000 a $2010^{3}$ a imigração aumentou 86,7\% -, dados aferidos pelo IBGE, Instituto Brasileiro de Geografia e Estatística (2010), é premente que se conheça como as escolas recebem as crianças estrangeiras e como seus pais veem o atendimento aos filhos nas instituições escolares, além de conhecermos se os alunos estrangeiros estão inseridos na realidade e cultura brasileiras. O grupo de pesquisa Movimentos Migratórios e Educação é composto por mestrandos e doutorandos do Programa de Estudos Pós-Graduados em Educação: Escola, Política, Sociedade da PUC-SP. Os trabalhos do grupo têm o objetivo de estudar as imigrações recentes para o Brasil, em termos de caracterização das mesmas, mas, além disso, busca conhecer como ocorre a inserção social e cultural desses imigrantes e de crianças estrangeiras na escola pública e privada brasileira, especialmente na cidade de São Paulo, campo da nossa pesquisa. Os trabalhos publicados pelo grupo, logo no

\footnotetext{
${ }^{2}$ Além do grupo de pesquisa já citado, o Centro de Estudos Rurais e Urbanos (CERU) da USP - do qual participo - colabora com o aprofundamento das discussões sobre o tema e a divulgação do nosso trabalho.

${ }^{3}$ As pesquisas (IBGE) apontam que no ano 2000 viviam no Brasil 143.644 imigrantes e em 2010, 268.201 imigrantes, ou seja, um aumento de $86,7 \%$. Os censos demográficos no Brasil ocorrem de dez em dez anos.
} 
seu início, referiam-se, em boa parte, aos resultados de dissertações e teses desses mesmos estudantes. Esses resultados, à época - 2014 - foram se aprimorando em função dos objetivos do grupo, com base em novos dados e novas análises, processo esse que se entende pelo número de leituras que foram feitas pelo grupo e pelas informações coletadas posteriormente, incluindo novas observações e novas entrevistas coletadas. Nesse grupo de pesquisa estão professores de outras instituições, nacionais e estrangeiras além de alunos de outros programas de pósgraduação da PUC - SP e de fora dela, mas que têm interesses em comum de pesquisa. As investigações estão sob minha orientação sendo realizadas pelos participantes, diretamente envolvidos no trabalho. Essa busca de informações, sejam elas por entrevistas ou observações, são organizadas de modo que ocorram em cada semestre de trabalho, de acordo com os objetivos da pesquisa e a disponibilidade dos participantes. As informações quantitativas quanto ao número de imigrantes no Brasil são investigadas, selecionadas e retiradas dos trabalhos do IBGE que nos auxilia e muito, no desenho geográfico e numérico dos imigrantes no Brasil e fornece bases para importantes interpretações. O mesmo ocorre com as informações quantitativas fornecidas pelas secretarias de educação do Estado e do Município de São Paulo, valiosos dados sobre crianças estrangeiras matriculadas em nossas escolas. Esses dados brutos são fornecidos e cabe aos pesquisadores do grupo selecioná-los e organizá-los de forma adequada para podermos responder aos objetivos propostos pela pesquisa.

Os dados do IBGE em 2014 mostravam que a maior imigração para o Brasil no período, após o último censo realizado em 2010, tinha e ainda tem origem na América do Sul, mas não se restringe a ela. Atualmente recebemos imigrantes em grande número de certos países da África (Congo, Angola), Ásia (Bangladesh, China), Haiti (Caribe), além de muitos imigrantes de países vizinhos ao Brasil. Estes se constituem como um dos maiores focos de migração e, atualmente, considerando todos esses imigrantes, predomina a de bolivianos, paraguaios, peruanos e venezuelanos, estes os mais recentes. Dizemos uma das maiores porque, oficialmente, dados coletados em 2010 pelo IBGE demonstram que, entre todas as imigrações a maior imigração para o Brasil é a de americanos dos EUA do Norte (51.933 americanos), seguida pela do Japão (41.417 japoneses) $)^{4}$. Entretanto, se essas duas imigrações são importantes, elas se diferenciam da imigração Sul-Sul porque esses migrantes são de certa

\footnotetext{
${ }^{4}$ Os dados do IBGE sobre imigrantes no Brasil, em 2010, apontam, dentre todos os imigrantes - de um total de mais de trinta nacionalidades diferentes - as cinco maiores imigrações: EUA, 51.933; Japão 41.417; Paraguai, 24.666; Portugal 21.376 e Bolívia, 15.753 imigrantes. Aqui, alertamos que esses números podem ser maiores, já que o IBGE considera imigrante aquele que tem documentação, portanto esses dados podem sofrer alteração para maior.
} 
forma bem-vindos em função de serem sujeitos com profissões definidas e interessantes para o desempenho de certas profissões no mercado de trabalho brasileiro, para as quais se exige maior formação; esse é especialmente o caso do imigrante norte-americano. No caso da imigração japonesa, pode-se dizer que se trata de um movimento constante, em função da grande colônia japonesa que aqui já está instalada, de forma que são gerações e gerações que mantêm contato. Essa antiga imigração (início do séc. XIX) não se trata e não se compara com a migração atual, porque se consolidou no Brasil, especialmente no Sudeste e no Sul, enquanto a atual aloca imigrantes de vários países por todo o território brasileiro.

Atualmente, o que predomina no Brasil é a imigração Sul-Sul. Neste caso o Brasil era considerado, em 2014, no momento da criação do grupo de pesquisa citado acima, o maior país da América do Sul enquanto determinante da política econômica do Mercosul. O Brasil encontrava-se em pleno desenvolvimento (na era dos treze anos dos governos do PT, Lula e Dilma - 2003-2016) e era o maior país em potencial econômico da América do Sul. Assim, passou a atrair muitos imigrantes do Sul e em menor número imigrantes do Norte e dos países do Oriente Médio, como a Síria. Neste último caso, se desconsiderarmos as razões prementes da imigração síria, o Brasil é um país que recebe os sírios desde o século XIX, portanto estes também já têm aqui uma colônia estabelecida, o que facilita a migração.

Essas são algumas considerações sobre o objeto e contexto geral da nossa pesquisa, que passo a detalhar mais no que se refere a seus procedimentos. Realizamos entrevistas e, com base em algumas delas, observamos que a imigração atual não se trata mais de uma imigração laboral, simplesmente, e de posse desses dados e estudos escolhemos alguns autores que discutem as possíveis formas de analisar a imigração, hoje. Se a imigração não tem mais como razão fundamental o trabalho, o que então levaria os agentes a migrarem? Sabemos, desde estudos da Escola de Chicago, sobre a imigração americana e especialmente em Chicago, iniciados por volta de 1917 (Jeseph; Grafmeyer, 2004) $)^{5}$ e trabalhos importantes de Sayad (2010), que a imigração ocorria em busca de trabalho, para sobrevivência. Para exemplificar, consideramos algumas das imigrações europeias para os EUA - já especificadas em nota de rodapé anterior - e as que tiveram como base acordos entre países europeus e Brasil, por

\footnotetext{
${ }^{5}$ Joseph e Grafmeyer. L' École de Chicago. Flammarion, Paris, collection Champs Assais, 2004. Os autores analisam a imigração em Chicago, "Chicago, Ville d' immigrants" - allemands, italiens, russes, polonais, irlandais, suédois, autrichens, hongrois, tchécoslovaques (...) e muitas outras nacionalidades, informação retirada da tabela "Pourcentage d'étrangers en 1920, p.308. Nesse período é que se coloca o movimento migratório como fenômeno social tido como um problema e por essa razão é que se elege a Sociologia como disciplina para estudá-lo, no caso a sociologia urbana.
} 
exemplo, no final do séc. XIX e início do século XX, como foi o caso dos italianos, espanhóis, portugueses, alemães, suíços e, mais tarde, em grande número os imigrantes japoneses. Muitas dessas imigrações tiveram origem no final da segunda Grande Guerra Mundial, que ocasionou um desastre nas condições políticas, sociais e econômicas dos países que estiveram envolvidos com a guerra.

Decorrem do fenômeno migratório vários outros aspectos sociais, já que ele por si só já é um elemento fundamental para se compreenderem as sociedades que passaram e passam por esse processo. Muitos explicitariam tal aspecto social (imigração), basicamente como um problema, proposição esta da qual discordamos e vamos tratar em seguida. Temos como base o trabalho de Castles (2010), que analisa a ideia de que a imigração não pode ser vista apenas como um problema sociológico. O autor desenvolve a ideia de que esse é um fenômeno que envolve aspectos sociais, econômicos, políticos e, atualmente, também problemas geopolíticos e fronteiriços. Não que esses dois últimos aspectos não fossem características de outros momentos migratórios, mas atualmente, com o avanço de um "novo imperialismo", impôs-se a ideologia de que não se trata de imperialismo e, sim, de um mundo globalizado no qual, teoricamente, as fronteiras não devem existir, ao menos no que diz respeito ao capital financeiro e às diversas formas de "acumulação"7 do capital. Mas as fronteiras continuam a existir para a “imigração não desejada" 8 e aí se impõem as preocupações geopolíticas. Além disso, lembremos que a imigração envolve aspectos do indivíduo que são fundamentais para sua sobrevivência, tais como garantir sua identidade individual e cultural neste novo território; são aspectos identitários que o caracterizam como ser detentor de determinados aspectos físicos e culturais que o diferenciam do outro - alteridade - quando lembramos que este migrante terá de se inserir (ou não?) no grupo social. Além disso, não se pode esquecer que a cultura, território, territorialidade ${ }^{9}$ serão carregados pelo migrante para sempre, neste novo território. Na verdade, as suas bases territoriais jamais serão abandonadas, pois fazem parte da sua memória e essência.

O artigo, após essa introdução, apresenta um item onde discute o referencial teórico de Castles, inspiração para o objetivo definido nesta primeira sessão, além de outros autores; outro item explicita os procedimentos de pesquisa empregados na coleta das entrevistas com

\footnotetext{
${ }^{6}$ Proposta desenvolvida por David Harvey (2004).

${ }^{7}$ Idem. Harvey considera todo tipo de acumulação do capital, mas enfatiza a acumulação por espoliação.

${ }^{8}$ Termo bastante conhecido para se referir aos migrantes negros, indígenas, pobres e com pouca qualificação, e muito bem descrito por Sayad e Bourdieu (1998).

${ }^{9}$ Para melhor compreender as definições de território e territorialidade e a importância desses conceitos na determinação da cultura e identidade do agente social, ver trabalho de Henri Lefebvre (2000) e Rogério Haesbaert (2011).
} 
imigrantes e a definição aleatória de três delas, dentro de um conjunto de vinte entrevistas, até então; ainda neste item, ao apresentar as entrevistas desenvolvo a análise das falas com base no referencial teórico; por último seguem as considerações finais possíveis com base nesse pequeno grupo de entrevistas e análises.

\section{A imigração segundo alguns autores atuais}

Castles (2010), na busca de uma teoria que pudesse vir a responder as razões das imigrações, aponta a insuficiência de uma só área de estudo para esse fenômeno. Segundo ele, é preciso considerar a pesquisa sobre imigração como um fenômeno mais abrangente da sociedade. Deve-se considerar a interdisciplinaridade para que possamos ter uma visão da totalidade do fenômeno. Por princípio Castles considera que todas as sociedades se transformam, umas mais, outras menos, mas é inevitável que isso ocorra e, considerando o contexto de aceleração da transformação global, teríamos que enxergar essa mesma transformação nos processos migratórios. Ou seja, por que o agente social migra atualmente, dentro desse novo contexto? Com certeza não é pelas mesmas razões que impulsionaram as migrações do final do século XIX e início do século XX. Bem, se as razões mudaram, temos que responder porque mudaram e quais são as novas motivações. Isso implica ter em consideração os conceitos de neoliberalismo do séc. XXI e a ideia de globalização na qual o mundo social se insere na atualidade.

Assim, vamos partir de algumas definições importantes e verificar o quanto elas explicam as transformações sociais das sociedades e o quanto a crise capitalista é fator fundamental do aumento exponencial do fenômeno migratório. Essa crise expõe, principalmente para os países de Primeiro Mundo (do Norte), as dificuldades que têm para enfrentar esse processo migratório; imagina-se, então, as dificuldades dos países do Sul que acabam por repetir esse mesmo processo entre seus territórios e entre suas sociedades, sem as mesmas condições, com maiores dificuldades econômicas e sem a infraestrutura necessária. Por que a imigração do Sul em direção ao Norte não é prioritária? Talvez, com o desenvolvimento de algumas características sociais, políticas e econômicas dos países do Sul, neste texto, possamos encontrar uma resposta para essa última questão.

Concordando com Castles (2010), entendo que a melhor forma de podermos compreender as razões das imigrações atuais é a transformação pelas quais passam as sociedades capitalistas. A fase do capitalismo neoliberal, segundo Harvey (2004), apresentanos problemas econômicos que abalam drasticamente a inversão do capital e, por sua vez, o fim das condições de acumulação do capital. Essa análise de Harvey (2004) aponta para a saturação dos modos de produção capitalista, já que seu fundamento - o capital - não pode 
mais se expandir, dentro das próprias nações, tidas como de Primeiro Mundo e detentoras de todo poder econômico, político e geopolítico. É o caso dos EUA e dos países da Europa, especialmente França, Alemanha, Reino Unido. Esses países puderam crescer, desenvolver riqueza com a expansão do capital à medida que tinham condições de investir no crescimento dos bens produtivos, aumentando assim sua riqueza e seu poder. Mas, com a saturação desse crescimento econômico interno, as nações foram obrigadas a carregarem seus meios de produção para países emergentes, como é o caso da China, Índia, México, Brasil, Argentina, Bangladesh, entre outros, procurando nova forma de crescimento e de exploração da força de trabalho. Esses aspectos fundamentais para o capitalismo foram abalados à medida que não se pode aumentar a empregabilidade e não se podem expandir as indústrias, os bens de produção, por falta de crescimento econômico. Esse crescimento, por sua vez, fica na dependência da produção, que, por sua vez, é determinada pela demanda e pelo consumo, aspectos que deixaram de seguir seu rumo "natural", se é que assim pode ser denominada essa trajetória imposta por esse modo de produção. Dessa forma a falta de espaço econômico e territorial para crescimento do capital leva países ricos a dominarem países mais pobres para ocuparem seus espaços territoriais, implantando dentro deles indústrias e instituições financeiras que aparentemente oferecem condições para aumentar a empregabilidade, embora muitas vezes em condições quase escravistas e muito diferente das condições trabalhistas dos países ricos de onde se originaram essas mesmas indústrias e instituições. Esse novo imperialismo, que não se caracteriza pela tomada do território, explicitamente, é, implicitamente, uma forma de aumentar domínios geográficos por força do poder político, econômico e armamentista.

Estamos, portanto, vivenciando uma fase do capitalismo que impõe uma transformação social não almejada aos países ricos, à medida que esses, para não correrem o risco de diminuírem ainda mais suas riquezas, necessitam transpor fronteiras (de forma impositiva) para buscar condições de inversão rentável do capital. Essa transposição de fronteiras traz, aparentemente, a ideia de globalização, já que a produção de mercadorias, distribuição e consumo que ocorre no globo traz a falsa ideia de globalização no lugar de um novo imperialismo, pois a produção e o capital estão em todas as sociedades capitalistas. As grandes empresas dos países mais ricos, ao se deslocarem, deixam no país de origem muitos trabalhadores desempregados que terão, necessariamente, de procurar novas formas de trabalho para sobrevivência. Se isso não for possível dentro da sua própria nação, a tendência pode ser a de buscar trabalho em outros países, provavelmente em outros países do Norte. Esta é uma forma de imigração já conhecida, por busca de trabalho, embora as razões sejam outras, quando comparadas às razões antigas, como guerra, catástrofes naturais, perseguição política e ou 
religiosa. Fica claro, então, que os indivíduos têm que migrar em consequência da transformação econômica e social de seu país de origem. Não é algo que se faz de livre e espontânea vontade, o próprio movimento econômico da sociedade pode provocar a migração caracterizando-se como uma migração fruto das condições políticas e sociais, impostas pelas contradições criadas pelo neoliberalismo e pela nova forma de imperialismo. Aqui, é importante lembrar que esse novo imperialismo leva à expansão e acumulação do capital, mesmo que seja por espoliação, quer dizer, fazendo com que determinado território seja "desocupado" pela força imposta por privatizações de bens antes partilhados, como é o caso de terras camponesas. Conforme Harvey (2004),

A expulsão de populações camponesas e a formação de um proletariado sem terra tem se acelerado em países como México e Índia (...); muitos recursos antes partilhados, como a água, têm sido privatizados (com frequência por insistência do Banco Mundial) e inseridos na lógica capitalista da acumulação; formas alternativas (autóctones e mesmo, no caso dos Estados Unidos, mercadorias de fabricação caseira) de produção e consumo têm sido suprimidas. (Harvey, 2004, p. 121).

No caso de países mais pobres, chamados emergentes, ao serem ocupados por essas empresas que chegam para inversão do capital pode ser uma forma de empregabilidade esperada, entretanto as condições de trabalho são de superexploração do trabalhador dessa nação. Por isso vale muito transpor fronteiras para levar meios de produção para esses países onde os salários são muito baixos e as leis do trabalho são frouxas, quando existem.

É preciso lembrar que o neoliberalismo tem como proposta a ideia de um Estado cada vez menor, atuando cada vez menos em políticas públicas e pelo bem comum. Com isso, "indústrias nacionalizadas têm sido privatizadas. O agronegócio substitui a agropecuária familiar. E a escravidão não desapareceu (particularmente no comércio sexual)” (Harvey, 2004, p.121). Ademais, práticas espoliativas têm o apoio, incentivo e controle do Estado.

Com a prática de acúmulo de capital sem reinvestimento, ou seja, a sobreacumulação, fica claro que a espoliação é uma das formas de resolver esse problema. Esse acúmulo de capital sem reinvestimentos - sobreacumulação - ocorre porque o capitalista prefere acumular ao invés de aplicar esse capital em algo incerto ou com pouca margem de lucro. Daí o não desenvolvimento econômico e o subconsumo ${ }^{10}$ já que não há emprego e, portanto, não há

\footnotetext{
${ }^{10}$ Os conceitos de sobreacumulação, subconsumo e espoliação são de David Harvey, 2004, pp. 116-126.
} 
salário. Essa pode ser uma transformação política e econômica, dentre outras, que podem levar a uma transformação social de grande envergadura, gerando ou ampliando o fluxo migratório.

Aqui vemos que o capitalista pode reter o capital por tempo indeterminado e voltar a reinvesti-lo quando avaliar que existem vantagens. Por outro lado, todas essas estratégias, sejam eles de reter o capital para depois investi-lo, transpor fronteiras na busca de melhores formas de acumulação do capital, espoliação para resolver o problema da sobreacumulação não são preocupações do trabalhador, pois nada disso faz parte de sua realidade. Para ele sobram as consequências da sobreacumulação, na outra ponta do processo, o desemprego, tendo que lutar por formas diversificadas de sobrevivência. Assim, esse trabalhador busca muitas vezes tentar driblar a falsa ideia de "globalização" cruzando fronteiras na busca de condições de trabalho. Isto explica a denominação de "problema" para os processos migratórios.

\section{As teorias e os depoimentos de imigrantes atuais}

Até aqui buscamos mostrar as possíveis causas das imigrações atuais, apontando que elas podem acontecer pelas próprias condições do modo de produção capitalista em decadência e das estratégias escolhidas para sua salvação, o neoliberalismo e a globalização. Neste ponto do texto, trago depoimentos de alguns migrantes obtidos nas entrevistas realizadas por participantes do grupo de pesquisa que poderão reiterar o que propusemos desde o início do trabalho. As falas são respostas obtidas nas entrevistas, com base em questões elaboradas e apresentadas a esses migrantes procurando conhecer as razões da migração. De onde vieram? Por que migraram? Onde trabalhavam no país de origem? Atualmente, na cidade de São Paulo, têm uma ocupação, qual é? Participam de atividades culturais e sociais que representam sua nação, aqui? E com os nacionais, quais são as relações culturais e sociais? Aqui estão as falas de apenas alguns migrantes, dado o pequeno espaço para essa discussão sendo eles oriundos da Bolívia, Congo e Bangladesh. Apresentamos as falas obtidas nas entrevistas, buscamos relacioná-las com os conceitos acima desenvolvidas (neoliberalismo, globalização) e em seguida faremos uma síntese desses achados.

Entrevistamos o sr. Irineu, oriundo de La Paz, Bolívia. Veio para São Paulo em 2002. Tomou a decisão de vir para o Brasil porque a vida e o trabalho no campo boliviano - altiplano andino - estava difícil. Já havia morado cinco anos em La Paz antes de São Paulo, mas lá só fazia trabalhos esporádicos, principalmente de funilaria. Como já tinha irmãos aqui em São Paulo, resolveu vir e procurar trabalho aqui. Começou a trabalhar com costura, nas oficinas que 
ficam no Butantã onde também reside. Com o passar do tempo melhorou muito sua qualidade de vida aqui, porque todo o trabalho desses migrantes, antes num regime de informalidade, foi formalizado. Ele e a esposa têm hoje uma oficina que é deles e tudo que fazem de costura vendem diretamente para lojas de confecção no Brás, bairro da Zona Leste de São Paulo. Têm toda a documentação pessoal deles, são migrantes documentados e prestam todas as informações referentes ao trabalho que realizam - confecção e venda de roupas - ou seja, emitem notas fiscais de todas as peças de roupas que são comercializadas, pagam impostos etc. $\mathrm{O}$ sr. Irineu e a esposa têm hoje todos os direitos que um trabalhador tem com carteira de trabalho.

Com relação aos serviços básicos fornecidos pelo Estado brasileiro, o sr. Irineu valoriza muito a escola do filho pela qualidade e, principalmente, porque a escola é muito mais "aberta", avançada em termos de ideias e valores. Nesse ponto ele relaciona as características da escola com as da sociedade brasileira, sendo esta muito mais avançada e com ideias de liberdade muito positivas, quando comparada com a sociedade e escola bolivianas, segundo ele. Enquanto migrante, já passou seis meses em Buenos Aires, logo depois de chegar no Brasil, mas, segundo ele, a sociedade argentina é muito mais preconceituosa com relação aos bolivianos que a brasileira. Não se acostumou lá e voltou para São Paulo.

Nesse caso, pode-se perceber que foi uma imigração decidida por conta própria (ou pelo sr. Irineu), não estava desempregado, mas procurava outras formas de trabalho e de vida. Percebe-se também a satisfação por ter conquistado uma sociedade menos conservadora que a boliviana, satisfação esta expressa na fala do Sr. Irineu quando se refere à escola do filho e da sua inserção (falando pela família) na sociedade brasileira. Disse ele, sobre isso, que tem amigos brasileiros e com eles tem atividades, por exemplo, jogar futebol, time que é formado por nacionais e imigrantes bolivianos. Entretanto, cita que uma vez sofreu discriminação por parte de brasileiros, que diziam: "hei boliviano, volte para seu país, está aqui tomando nosso lugar de trabalho", mas coloca essa discriminação de forma muito minimizada, pois admira e gostaria de aprender como os brasileiros conseguem ser tão amáveis, segundo ele. Fala mesmo de forma muito carinhosa sobre os brasileiros: "gostaria de aprender a amabilidade que aqui existe, aprender esse carinho do brasileiro".

Outra verbalização importante do Sr. Irineu: “diz que o serviço de saúde no Brasil é muito superior ao da Bolívia. Na Bolívia somente a consulta é gratuita, todos os demais procedimentos e internação hospitalar são pagos". Nesse ponto pode-se ver que essa condição 
"ainda existente no Brasil""11, como parte de um Estado que não acabou totalmente com os serviços públicos, é uma forma de atração para alguns imigrantes da América do Sul.

Sua perspectiva enquanto trabalho é mudar para o empreendedorismo, na área de alimentação. Está pensando nessa possibilidade, nos estudos e habilidades que precisa adquirir e as que pretende aperfeiçoar para poder apresentar e servir a comida típica boliviana. Essa perspectiva, a nosso ver, pode ser pensada no século XXI, pois foi nas dificuldades e nas crises do capitalismo contemporâneo que esse tipo de serviço passou a existir e a ser oferecido, principalmente aos que já perderam emprego e aos que buscam uma diferenciação no sentido da divisão social do trabalho, trabalho manual e intelectual. Aqui, não se trata de assumir um trabalho intelectual, mas um trabalho próprio, como um "empresário" e não mais como um empregado. Essa forma de trabalho tem sido a saída mais frustrante para boa parte dos trabalhadores manuais, pois não conseguem empreender conforme diz o discurso dos defensores do trabalho "próprio", o que não passa de uma grande ilusão, tendo de retornar à categoria de trabalhador assalariado. Só lhe resta entrar na fila dos desempregados ou dos que já não têm esperança de encontrar trabalho, é a fila do desalento e exclusão total do mercado de trabalho.

O sr. Irineu chegou aqui com dezessete anos e hoje está com trinta e dois, portanto faz quinze anos que migrou e não pretende voltar. Aqui em São Paulo estão todos os nove irmãos e sua mãe os visita, vez ou outra, e ele já tem casa própria e um automóvel. Segundo ele o imigrante aqui no Brasil é muito bem tratado, pelo menos quando é documentado, coisa que melhorou e facilitou muito depois do acordo Mercosul. Segundo ele, em São Paulo o Conselho Municipal do Imigrante, ligado à Secretaria de Direitos Humanos e Cidadania do município, colabora, e muito, para agilizar a legalização dos imigrantes e das atividades culturais desses grupos. Por último, ele tem ainda uma reivindicação importante: "pagamos todos os impostos que nos sãos cobrados, então é preciso ter o direito a voto nas eleições”.

Este é um dos casos de imigrante que tinha trabalho no seu país, no caso, era trabalhador no campo e depois na cidade de La Paz com ocupações esporádicas. Sua saída, como vimos, se deu pelo fato de procurar condições melhores de trabalho e isso foi possível porque já tinha irmãos que já estavam em São Paulo, vindos em anos anteriores. Além das condições relacionadas ao trabalho, hoje o sr. Irineu pretende permanecer em São Paulo por outras razões,

\footnotetext{
${ }^{11}$ Colocamos ainda existentes entre aspas por não termos nenhuma segurança sobre esses serviços públicos que devem ser obrigatórios e garantidos pelo Estado brasileiro, mas que no governo Bolsonaro tudo pode vir a ser destruído.
} 
muito valorizadas por esse migrante boliviano, o fato de viver atualmente numa sociedade mais aberta, menos conservadora, quando comparada com a sociedade boliviana. Nessa mesma direção, dá uma importância muito grande à escola do filho, aqui no Brasil, que avalia como muito boa além de dizer que a escola é mais aberta em termos de valores, ajudando muito no crescimento e educação do filho. O Sr. Irineu frisa que atualmente as condições de trabalho e mesmo de salário melhoraram muito na Bolívia, mesmo assim não tem intenções de voltar. Talvez o encontro de uma sociedade menos conservadora tenha conquistado sua permanência, fato este que pode ter sido enfatizado pelos irmãos que chegaram antes dele. Essas ideias e impressões sobre a vida em outra sociedade hoje é facilmente transportada para outros territórios, depois do aparecimento da internet.

Outro caso de imigração que se diferencia da imigração por trabalho é o caso de um imigrante africano, do Congo. Trata-se de um jovem já formado em Economia e no Congo vivia com a família, de origem social privilegiada. Seus pais fizeram ensino superior, o pai é engenheiro e a mãe é pedagoga. Escolheu vir para o Brasil para fazer o curso de artes cênicas; a razão para não fazer no Congo esta segunda graduação foi pela resistência colocada pelos pais. O motivo pelo qual veio para o Brasil foi estudar e se encontrar consigo próprio, procura de liberdade no que diz respeito a sua própria vida. Ele diz: Minha motivação foi de estudo. Somente para continuar a estudar. Já havia feito Economia, mas fez pela vontade da família; "já estudava economia, mas queria fazer arte, ser ator, fazer artes cênicas, cinema. Lá tem um instituto de arte, arte dramática”. Inscreveu-se para concorrer a uma bolsa pelo convênio PECG que existe entre alguns países da África e América Latina, Chile, Bolívia, Brasil. Além dessa bolsa o estudante que opta por ela deve ter outra forma de financiamento para se manter, porque a bolsa não cobre todos os gastos. No caso dele são os pais que pagam o restante. Segundo ele, há poucos estudantes aqui em São Paulo com essa bolsa, porque São Paulo é uma cidade muito cara e não teriam como completar a renda. Segundo Tresor, o número de congoleses em São Paulo que veio para estudar é muito pequeno. Outro motivo para Tresor vir ao Brasil foi conhecer o país e aprender outra língua. Por isso não foi para a Bélgica nem para o Reino Unido, porque o francês é sua língua materna e domina bem o inglês. Para esse imigrante que já estava no $5^{\circ}$ ano do curso de cinema e artes cênicas na UNIFESP conhecer o Brasil é seu maior desejo, principalmente no que diz respeito à cultura brasileira - música e teatro. Também, ter vindo para cá foi uma aprendizagem com relação ao racismo. Ele não conhecia essa forma de preconceito e ficou muito chocado quando chegou no Brasil e foi fazer um curso para aprender português no Rio Grande do Sul. Pelos seus estudos sobre o Brasil, sabia que "aqui vive uma concentração muito grande de negros, é a segunda maior concentração de negros do mundo, 
antes dele está a Nigéria”. Por essa razão não imaginava sofrer preconceito racial aqui, só mudou de ideia quando conheceu a população do Rio Grande do Sul. No dia seguinte à chegada neste Estado foi fazer sua documentação, "todo mundo branco, dentro do ônibus, olhava do lado, olhava nas escolas, todos brancos. Na minha cabeça eram alguns estudantes alemães que vieram estudar aqui, sei lá, estudar e voltar". Depois que começou a estudar na Universidade em São Paulo "percebeu que o racismo é meio velado. Eu nunca tinha passado por isso aí, também precisei passar para saber o que é isso. Percebi pela universidade que é um lugar que tem muitos brancos, que minha situação não era tão forte”. Em São Paulo, segundo Tresor, o número de negros é muito pequeno, e por isso ele sofre com o preconceito, algo que não havia sentido na pele. "Achava que chegaria aqui e veria o negro e o branco todos juntos, andando. Eu tinha isso na cabeça”.

No caso desse migrante, de classe social privilegiada e com formação educacional de nível superior e com nenhum motivo financeiro para migrar, podemos pensar que o fato de ele querer se distanciar da família e amigos que diziam para não vir e não fazer artes cênicas, é uma expressão de busca pela liberdade de escolha e de construção de uma vida diferente da imposta pela família. Este pode ser um caso de transformação individual que, por sua vez, tem a ver com os valores e relações sociais, talvez conservadoras, de sua sociedade de origem. Poderá, mesmo à distância (porque contata a família e conhecidos semanalmente) provocar o desejo de uma "desorganização" social (não facilmente), a longo prazo, à medida que outros jovens passem a desejar também seguir o caminho de Tresor. O conceito de desorganização, segundo Coulon (1995) foi desenvolvido por Thomas e Znaniecki em 1927 em seus estudos sobre a imigração polonesa para os Estados Unidos na Escola de Chicago. Após uma desorganização o grupo social passaria por uma organização e reorganização novamente, sobre novos patamares.

Outro caso de migração, este por razão mais tradicional é do migrante Partha . Perguntado de qual país ele veio ele respondeu "sou de Bangladesh, mas eu não me sinto de lâ". Disse ele que deixou o país "por causa da perseguição religiosa. Hoje são 9\% de hindus, e os hindus são inimigos do Estado, e minha família é hindu. Ou seja, hindus não conseguem empregos e enfrentam diferentes problemas". O caso de Partha trata-se de uma imigração por refúgio e esta é uma razão já esperada nos estudos de imigração, vejamos se há alguma particularidade na sua trajetória. Em termos do atual contexto, temos hoje no Brasil e especialmente em São Paulo muitos migrantes por refúgio, como é o caso dos sírios e de uma imigração islâmica, muçulmana e outras religiões; vêm do Sul da Ásia, Bangladesh, Mianmar, Sri Lanka, entre outros países. 
O que podemos considerar como específico dessa imigração no séc. XXI? Em primeiro lugar, trata-se de uma imigração por perseguição religiosa e essa perseguição, dentro do próprio país, traz como consequência, pelo estigma, a impossibilidade de relações pessoais, de trabalho, de acesso à educação, da aprendizagem da língua, portanto, um afastamento do convívio com os demais e da cultura própria do grupo religioso ao qual pertence e muito menos com os demais grupos. Trata-se, em geral, de uma imposição da religião da classe dominante do país natal, aos grupos minoritários. Todas as dificuldades enfrentadas por grupos minoritários em determinados países podem levar esses grupos a um nível desumano de sobrevivência, alcançando muitas vezes o status de imigração humanitária no país de acolhimento.

Segundo Partha, em Bangladesh ele vivia em Dhaka, mas, por causa da imposição religiosa, islamismo, sempre foi perseguido e censurado por ser hindu, religião que é considerada inimiga do Estado Islâmico. Por essas razões ele saiu sozinho de Bangladesh e já havia passado pela Índia, Noruega, Austrália e agora está no Brasil. Diz: “Eu não escolhi o Brasil, eu vim parar no Brasil porque sou um refugiado, não foi escolha minha". Em Bangladesh sua ocupação foi engenheiro de turno e na Austrália foi consultor de vendas, nível superior. No Brasil é professor de inglês e microempreendedor, tem uma empresa (escola) de idiomas. Diz ele: “Hoje recebo muito menos que na Austrália, fiz quase 100 mil dólares australianos em sete meses" comprovando esse recebimento com documento. Conta que, com a ajuda da Caritas ${ }^{12}$ em São Paulo, conseguiu trabalho como professor de inglês em uma instituição que ministra aulas com "intercambistas" dos mais diferentes países. As escolas situam-se na periferia de São Paulo. Já para abrir sua empresa ele encontrou muitas dificuldades; para conseguir o CNPJ e outros documentos precisou da ajuda de um advogado. Partha diz que o suporte que obteve no Brasil foi da Caritas, nunca teve suporte do governo; valoriza a Caritas "eles me fizeram sentir em casa. Eles me deram todo suporte em tudo, até legal”.

Quanto a sua inserção social no Brasil, ele diz que poderia ser melhor, se pudesse ter uma inserção social com outros migrantes de Bangladesh que estão em São Paulo, mas como a maioria deles é mulçumana ele continuaria a ser perseguido, pois sua religião é hindu. Assim, frequenta a Calvary Internacional Church, uma igreja que congrega uma maioria americana, $50 \%$, segundo ele, e o restante são pessoas dessa igreja que também falam inglês. Aí ele se

\footnotetext{
${ }^{12}$ Caritas Internacional é uma confederação de mais de uma centena de organizações humanitárias da Igreja Católica. Sua missão é trabalhar para a construção de um mundo melhor, especialmente para os pobres e oprimidos. Em São Paulo ela é uma ajuda fundamental no acolhimento de imigrantes.
} 
sente incluído, por poder falar inglês, sem problemas. Em termos da sua língua oficial, o bengali, ele só poderia mantê-la se pudesse se relacionar com os demais de Bangladesh que aqui estão, mas não o faz por serem de outra religião. Quanto ao português praticamente aprendeu sozinho, ouvindo outras pessoas e relacionando a fala com as ações. Ao longo do tempo foi aprendendo melhor porque as pessoas vão corrigindo sua fala. Com relação à igreja que frequenta, ele considera que lá "é um bom lugar para criar relações com pessoas que querem ser exemplos na vida dos outros, querem fazer coisas boas. Esses bons exemplos me ajudam”.

Este caso do migrante de Bangladesh mostra que suas razões para migrar são claramente conhecidas e já estudadas, pois saiu por motivos de perseguição religiosa. Entretanto, o que é diferente no caso dele é sua forma de inserção, que deve ser o mesmo para outros que migram pela mesma razão. Ele não pode conviver naturalmente aqui por não ter uma comunidade hindu onde possa se inserir, independentemente de serem ou não de seu país de origem. Portanto, aqui ele é um migrante refugiado que continua, embora em termos, a ser perseguido pelos seus pares mulçumanos. Isso deve ocorrer com outros tantos mulçumanos, islamitas, hindus que hoje fogem de perseguições em outros países. O contexto social do século XXI obriga que as migrações ocorram dadas as condições impostas para isso; no país de origem as relações sociais e condições de sobrevivência não permitem a permanência do nacional que tem religião diferente da universal, dentro dele próprio, de forma que a intolerância se dissemina. Da mesma forma, como se têm notícias, dados os meios de comunicação e redes sociais atuais de um ou outro migrante de determinada nacionalidade em países onde a questão religiosa não é fator de imposição estatal - como ocorre em Bangladesh - esses territórios, como, por exemplo, o Brasil, passam a ser procurados pela população perseguida. Paradoxalmente essa é uma imigração que não tem uma comunidade na qual se possa apoiar, desenvolver e celebrar sua cultura, nem mesmo da própria língua. Isso pode ocorrer em muitos outros países que se apresentam como opção para refugiados, mas certamente não imaginam que mesmo nesse outro país possa existir perseguição por parte de seus "conterrâneos", de outra facção religiosa. É que os fluxos migratórios aumentaram muito em função das formas de comunicação e de transporte, isso é inegável; as notícias de um país para outro chegam muito rapidamente proporcionando informações necessárias para os que buscam refúgio, no caso das perseguições religiosas ou políticas; da mesma forma que se recebe uma notícia fica-se informado de modificações da mesma, essas anteriormente levavam meses para serem conhecidas. Os meios de comunicação via internet e mesmo os meios de transportes proporcionam tomadas de decisões e escolhas num piscar de olhos. Rapidamente o grupo de imigrantes que era seu inimigo (mulçumanos) no 
seu país de origem (Bangladesh), passa a ser refugiado, acolhido no mesmo território (São Paulo) onde está o grupo antes perseguido (hindu), dando continuidade à perseguição, algo inesperado, talvez. Outro aspecto da imigração de Partha é que ele (engenheiro de turno), tanto quanto o boliviano (trabalhador no campo, altiplano), embora empregados em seus países resolveram migrar e aqui, mesmo tendo encontrado trabalho assalariado buscam desenvolver a atividade de empreendedorismo, como opção caracterizada como melhor. Dessa forma, seguem as regras da ideologia do capitalismo neoliberal. A imigração, quando tinha como razão fundamental o trabalho, o imigrante se estabelecia depois de alcançar essa condição necessária e suficiente, embora com a expectativa constante de buscar melhores postos de atuação. Agora não se trata só desse movimento; a realidade capitalista mudou e a forma imposta pelo neoliberalismo e globalização (novo imperialismo) obriga o trabalhador a sonhar mais alto não como força de trabalho, mas com a falsa ideia de proprietário e de uma "empresa". Infelizmente, o empreendedorismo é a forma utilizada pelos Estados capitalistas neoliberais de não se responsabilizarem pelo alto número de desempregados e apontar com a falsa ideia de que esse não é problema da gestão do Estado. Empurram para o trabalhador a ideologia de que tudo é uma questão de mérito e cabe a ele buscar novas formas de sobrevivência.

\section{Considerações Finais}

Este trabalho, embora tenha considerado somente três entrevistas, das muitas já realizadas, pretendeu apontar que a imigração não é um problema para os Estados e que o imigrante não escolhe migrar, ele é sugado pelas adversidades capitalistas e carregado para outros territórios onde, na maioria das vezes, não é aceito.

No caso do migrante do Sul, a tendência é que se dirija para outros países do Sul, onde provavelmente poderá entrar no mercado de trabalho, que aceita mão-de-obra menos qualificada e onde, infelizmente, mesmo os mais qualificados são alocados no mercado de trabalho em funções de baixa qualificação. Para o Norte, o migrante do Sul sofreria muito mais com as exigências legais, qualificação para o trabalho e principalmente com os preconceitos voltados para a cor da pele, religião e o "carimbo" de potenciais terroristas. O texto de Castles (2010) contribui para que estudiosos da imigração repensem em como compreendê-la e explicála.

A análise aqui desenvolvida, com os objetivos específicos deste texto, pode fornecer elementos que indicam razões diferentes para a imigração atual, uma vez que ela não se trata essencialmente da razão laboral, isso no Brasil e no mundo. Os indicadores apontados sobre a 
crise do capitalismo atual - neoliberalismo, globalização, imperialismo, preocupações geopolíticas, problemas fronteiriços, sobreacumulação e a superexploração do trabalhador fazem sentido quando relacionados com os movimentos migratórios contemporâneos. De fato, as entrevistas aqui retomadas parecem apontar para o fato de que a transformação social pela qual passam as diferentes sociedades, tanto as de primeiro mundo que no geral recebem os imigrantes, como as sociedades de países mais pobres, que de certa forma promovem a emigração, pode ser fator fundamental na decisão de migrar, atualmente.

Com o cuidado de não generalizar as informações até aqui analisadas, parece-nos que os pesquisadores do tema imigração poderiam aprofundar essa discussão em busca de mais evidências sobre as razões da imigração atual. Os fatores aqui apontados podem de fato nos aproximar de uma possível explicação para os movimentos migratórios, mas temos ainda muito o que pesquisar sobre esse objeto. Espero que este texto possa ser um estímulo para novas buscas sobre o tema imigração e principalmente para evidenciar, ao longo dos estudos, se a transformação social (não importando qual e nem mesmo a intensidade) pode mesmo ser uma das razões principais das imigrações atuais. Se isso se confirmar, o "problema" da imigração seria fruto das sociedades capitalistas atuais, das crises sem precedentes desse modo de produção (criadas pelos dominantes nessas sociedades, agudizando as desigualdades entre as classes) e não de agentes sociais dispostos a trocar sua territorialidade por outra desconhecida e sem enraizamento. Outro ponto que merece ser aprofundado é que, dependendo do imigrante e da sua origem social, a migração pode ser uma busca de novas formas de vida, com possibilidades de experimentar sociedades mais abertas, menos conservadoras realizando desejos antes impossíveis no seu território de origem. A busca pelo novo, o desafio de enfrentar as condições materiais adversas por parte do migrante é constante e o pesquisador necessita seguir esses passos. 


\section{Referências Bibliográficas}

Brasil. Instituto Brasileiro de Geografia e Estatística. Censo Demográfico 2010. Disponível em: http://www.ibge.gov.br/estadosat/temas.php?sigla=sp\&tema=censodemog2010_migra

Castles, Stephen. Contextualização - Entendendo a Imigração Global. Revista Internacional de Mobilidade Humana, Brasília. Ano XVIII, n 35, p. 11-43, jul./dez. 2010.

Coulon, Alain. A escola de Chicago. Campinas: Papirus, 1995.

Haesbaert, Rogério. Concepções de território para entender a desterritorialização. In: Santos, Milton. (et alii). Território, territórios ensaios sobre o ordenamento territorial. Rio de Janeiro: Lamparina, 2011.

Harvey, David. O novo imperialismo. São Paulo: Loyola, 2004.

Joseph, Isaac; Grafmeyer, Yves. L'école de Chicag: Naissance de l'ideologie urbaine. Paris : Champs essais, 2004.

Lefebvre, Henri. La production de l'espace. Paris: Anthropos, 2000.

Sayad, Abdelmalek. La doble ausencia. Anthropos, Barcelona, 2010.

Sayad, Abdelmalek . A imigração ou os paradoxos da alteridade. São Paulo: Edusp, 1998.

Thomas, W.; Znaniecki, F. The polish peasant in Europe and America. Nova York: Knof, 1927. 